\title{
Zum Gedenken an Arno Forchert (1925-2011)
}

von Walter Werbeck (Greifswald)

Mit Arno Forchert, der am 10. März 2011 im Alter von 85 Jahren in seinem Detmolder Haus gestorben ist, hat die deutsche Musikwissenschaft einen Forscher, vor allem aber einen Lehrer von hohen Graden verloren. Wie gut er es zudem verstand, mit den richtigen Personen auch organisatorisch die richtigen Weichen zu stellen, bezeugt das Detmolder Musikwissenschaftliche Seminar, das er gegründet und während seiner aktiven Jahre nachhaltig geprägt hat.

Begonnen hatte alles in Berlin. Nach Kriegsdienst und Verwundung studierte Forchert in seiner Heimatstadt seit 1947 Musik (Hauptfach Klavier); sein Geld verdiente er auch als Pianist in amerikanischen Bars. 1950 wechselte er an die Freie Universität zur Musikwissenschaft, wo er 1957 bei Adam Adrio mit einer Arbeit über das Spätwerk des Michael Praetorius promoviert wurde. Damit hatte er sich die protestantische Musikkultur des frühen 17. Jahrhunderts als ein Forschungsgebiet erarbeitet, das ihn lebenslang nicht mehr losließ.

Freilich wurde am Berliner Seminar nicht nur geforscht, sondern auch musiziert; Forchert, seit 1959 wissenschaftlicher Assistent, sang im Chor und dirigierte das Collegium musicum. Nebenbei leitete er einige Jahre das Musiklehrerseminar am Konservatorium John Petersen in Zehlendorf, unterrichtete Musikgeschichte an der Kirchenmusikschule in Spandau, arbeitete als freier Mitarbeiter beim RIAS, schrieb Einführungen zu den Programmen der Philharmoniker, wirkte als Gutachter bei Urheberrechtsprozessen und gehörte Jahre lang zu den Schallplattenrezensenten von Fono Forum ebenso wie zur Jury des Deutschen Schallplattenpreises. 1967 habilitierte er sich mit „Studien zum Musikverständnis im frühen 19. Jahrhundert" und vier Jahre später folgte er einem Ruf auf die Stelle eines Professors für Musikwissenschaft an der Nordwestdeutschen Musikakademie in Detmold.

Mit einem ansehnlichen Kapital als Forscher und Lehrer, als praktischer Musiker und Kenner von Rundfunk und Schallplattenindustrie trat Forchert sein neues Amt an. Leicht war der Start dennoch nicht: hier die ostwestfälische Musikhochschule, an der die Wissenschaft ganz im Schatten der Praxis stand, dort ein ehrgeiziger ehemaliger Berliner, der sich fest vorgenommen hatte, dieses Ungleichgewicht zu beenden. Das dauerte allerdings einige Jahre und ging nicht ohne Bundesgenossen. An der Universität Bielefeld suchte Forchert sie vergeblich, an der Gesamthochschule Paderborn fand er sie. 1977 wurde das Musikwissenschaftliche Seminar in Detmold eingerichtet; 1981 wechselte Forchert mit seinen Kollegen an die Paderborner Universität, um das Seminar in eine gemeinsame Einrichtung beider Hochschulen zu überführen.

Kein Wunder, dass in all diesen Jahren die Zeit großangelegte Forschungsprojekte kaum noch zuließ. Dennoch blieb Forchert im Fach präsent und machte mit grundlegenden Arbeiten auf sich aufmerksam: zum „Malinconia“-Satz von Beethovens op. 18,6 beispielsweise, zu Scherings Beethoven-Deutungen oder etwa zum Begriffspaar klassisch-romantisch in der Musikliteratur des frühen 19. Jahrhunderts. Mit Studien zu 
Mendelssohn und Schumann, zu Mahler und Strauss blieb er im 19. Jahrhundert präsent, mit einem Klassiker wie „Musik und Rhetorik im Barock“ wusste er auch zum 17. Jahrhundert Gewichtiges zu sagen und mit seiner späten Bach-Monographie krönte er seine Studien zur Musik des 18. Jahrhunderts.

Besondere Freude machte ihm allerdings weniger "das Schreiben von mehr oder weniger belangvollen Abhandlungen" (so schrieb er mir einmal 1997) als vielmehr das Unterrichten. Höchste Maßstäbe an wissenschaftlicher Solidität wusste er mit höchster Anschaulichkeit der Darstellung zu verbinden. Dabei erwartete er von seinen Studenten die gleiche uneingeschränkte Identifikation mit dem Gegenstand, wie er sie selbst immer praktizierte. Regelmäßig unterrichtete er über sein Deputat hinaus und nahm sich noch Zeit, donnerstagabends zu einer kleinen Runde in sein Haus einzuladen, um Texte zur Musikästhetik und Philosophie gemeinsam zu lesen und zu diskutieren. Konkurrenz hatten solche Themen allenfalls von einer Fußballweltmeisterschaft zu fürchten. Forcherts Passion für den Fußball war notorisch. Als er bei einem Hochschulfest dem schiedsrichternden Kollegen Giselher Klebe vergeblich die Abseitsregel beizubringen versuchte, wurde er kurzerhand als Linienrichter eingesetzt und versah den Posten, wie nicht anders zu erwarten, mit Akribie und Leidenschaft.

Obwohl Arno Forchert sich nie aufdrängte, wurde ihm eine Reihe von Funktionen und Ämtern angetragen. In den 1980er Jahren diente er längere Zeit der Gesellschaft für Musikforschung, zunächst als Vorsitzender der Fachgruppe Musikwissenschaft und Musikpädagogik, später im Vorstand. Außerdem amtierte er als Beirat Musik am GoetheInstitut München sowie als Gutachter und stellvertretender Vorsitzender des Fachausschusses Kunstwissenschaft der Deutschen Forschungsgemeinschaft. 1988 bis 1997 steuerte er als Präsident der Internationalen Heinrich-Schütz-Gesellschaft deren Kurs über die Zeit der Wende hinweg; seine Verdienste dankte ihm die Gesellschaft später mit der Verleihung der Ehrenmitgliedschaft. Für sein wissenschaftliches Werk war er schon 1985, zum 60. Geburtstag, mit einer Festschrift geehrt worden.

Folgenlos blieben die jahrelangen Anstrengungen nicht. Immer wieder mit Krankheiten kämpfend, zog sich Forchert nach seiner Emeritierung bald zurück. Eher skeptisch nahm er neue Trends im Fach wahr, mischte sich aber nicht mehr ein. Mit Befriedigung erfüllte ihn Ende 2010 der Abschluss der Gesamtausgabe der Werke Johann Hermann Scheins, deren Betreuung er von seinem Lehrer Adrio gleichsam geerbt hatte: Vermächtnis eines Forscherlebens, das kurz darauf endete. 